\title{
The Role of Symbolic Capital in Stakeholder Disputes: Decision-making concerning intractable wastes
}

\author{
Suzanne Benn ${ }^{\mathrm{a}}$ and Richard Jones ${ }^{\mathrm{b}}$
}

\begin{abstract}
This paper examines almost thirty years of disputation concerning the disposal of the world's largest stockpile of the toxic organochlorine, hexachlorbenzene. It describes the study of a chemicals company in its attempt to manage the disposal of the toxic waste in a collaborative fashion with government, environmentalists and the local community. The study describes the new processes and structures specifically designed to address the decision-making and the issues of stakeholder perception and identity construction which have influenced the outcomes. Decision-making in such disputes is often theorized from the perspective of the emergence of highly individualized and reflexive risk communities and changing modes and expectations of corporate responsibility as a result of detraditionalization. We argue that the stakeholder interaction in this study reflects competing discourses in which corporate actors prioritize the building and maintaining of identity and symbolic capital rather than an active collaboration to solve the ongoing issue of the waste. As well, issues of access to expert knowledge highlight the relationship between conditions of uncertainty, technoscientific expertise and identity. The events of the
\end{abstract}

\footnotetext{
${ }^{a}$ School of Management, University of Technology Sydney, PO Box 123, Broadway NSW 2007 Australia; Suzanne.Benn@uts.edu.au
} 
study highlight the challenges faced by contemporary technoscientific corporations such as chemicals companies as they must deliver on requirements of transparency and openness, while maintaining technoscientific capacity and strong internal identity. We conclude that the study demonstrates the co-existence of social processes of individualization and detraditionalization with quasi-traditions which maintain authority, thus challenging the radical distinctions made in the literature between modernity and late or reflexive modernity.

Keywords: symbolic capital, risk society, stakeholder interaction

\footnotetext{
${ }^{\mathrm{b}}$ Department of Marketing, Copenhagen Business School, Solbjerg Plads 3, 2000 Frederiksberg; rj.marktg@cbs.dk
} 


\subsection{Introduction}

This paper aims to explore the discourses concerning the disposal of the world's largest stockpile of the highly toxic organochlorine, hexachlorbenzene (HCB). The stockpile of HCB is located on the site of Orica, one of Australia's most prominent chemicals companies, and previously one of the arms of ICI Australia. This case is analysed from the perspective of symbolic capital, which provides a powerful conceptual framework for analysing the social interactions between stakeholders in one of Australia's most intractable environmental problems. This perspective sheds light on the symbolic, rather than strictly environmental, aspects of a dispute that has spanned nearly three decades (from late 1970s till date of writing in 2007) in order to develop a deeper understanding of the nature of the dispute and its repercussions fro similar disputes. The analysis draws from concepts of identity and discourse reflecting the growing interest in application of what might be called broadly rhetorical approaches to the study of external stakeholder interactions. The rhetorical approach to organization communication sees discourse and rhetorical approaches as being complementary although distinct ways of critically examining communication acts (Dean, 1992; Livesey, 2002). In this way the paper aims to add to our understanding of how discourses create rather than reflect the outcomes of these disputes or as Hardy, Lawrence and Grant (2006: 60) put it, 'how language constructs organizational reality'. We also note the process of iteration, in that discourses both order and are ordered by the interactions between stakeholders. We define discourse as 'the practices of talking and writing, the visual representations, and the cultural artifacts which bring organizational 
related objects into being through the production, dissemination and consumption of texts' (Grant et al 2005: 6)

Our particular interest is why decision-making on this stockpile has proved as intractable as the waste itself. The paper raises a number of questions for the management of stakeholder relations in terms of our fundamental understanding of the processes of knowledge formations and identity construction that lie behind them. The study is highly significant for corporate managers in the $21^{\text {st }}$ century. One of the areas of most rapid change in corporate relations is in stakeholder interaction to do with environmental disputes. Under global conditions of economic liberalism, it has been suggested that relationships and activities of civic society are prioritized over government intervention (Beetham, 1993; Bellamy, 1999; Matten and Crane, 2005). We seek to ask the question: How do they reflect changing expectations of corporate citizenship?

Globalised information systems mean that corporate brands and reputations can be readily challenged. As a result, it is purported that corporations now trade in symbolic and reputational (Petrick et al, 1999), as well as economic, capital. Reputation is closely linked to identity - that central distinctiveness that emerges iteratively from the complex and dynamic interactions between organizational members and their stakeholders (Scott and Lane, 2000). In this context we explore the iterative relationship between reputation and identity and the processes and 
outcomes of stakeholder interactions. Environmental disputes have been closely linked to the emergence of the risk society (Beck, 1992). They reflect conditions of considerable uncertainty, not only in regard to the determination of the environment consequences of the issues, but also in terms of the web of stakeholders that become involved in these disputes and the ways in which the issues are framed and communicated in the reciprocal interactions between these stakeholders (Hajer, 1997; Tsoukas, 1999). We therefore ask the question: what issues of corporate interaction related to reputation and identity have prevented the company reaching a mutually satisfactory agreement with other stakeholders on the issue of the waste disposal?

The paper briefly introduces leading theoretical understandings of the changing relationships between corporations, governments and communities. Here the concept of symbolic capital is presented as it relates to the concepts of stakeholder relations and identity. The socially contested nature of the study makes it particularly suited to a discourse analysis where we argue that this instance is less about finding rational solutions to a pre-given problem and more about defining what the problem is as a pre-requisite to constructing common understandings. It is argued that this study can be understood in terms of competing discourses that represent institutionally bound socially constructed realities. 
Symbolic capital is defined here as the accrued symbolic wealth in the form of goodwill that a person or organization has built up as a result of symbolic interactions in its social network and that can be mobilised to legitimate actions both past and present. We use the concept of symbolic capital to underline the symbolic interactionist approach to this paper which sees interactions as essentially concerned with building and maintaining reputation and achieving legitimacy. We see symbolic capital therefore as distinct from social capital, which is defined by scholars such as Putnam (1996) and Nahapiet and Ghoshal (1998) as the social features such as the norms and trust that enable stakeholders, participants or employees to act together more effectively.

In analysing this study this paper adopts a symbolic interactionist (Blumer, 1969) and social constructivist (Berger \& Luckmann, 1966) approach. It sees humans as active participants in constructing, defining and enacting the realities to which they purport to respond (Rorty, 1979; Gergen, 1982; Weick, 1979). Human interactions, including the interactions between and within social constellations, such as companies and local pressure groups, and the communication around them, are therefore seen as reflections of constructed realities. Importantly, knowledge about an issue, such as the one dealt with in this study, is constructed through interaction within and between groups. Interaction within the group tends to confirm constructed realities and organizational concerns; interaction between groups tends to confirm "selfness" (Simmel, 1964) and further confirm the knowledge of the group. The interactions that we describe in this study can be seen as ongoing dialogues between parties that are constrained by their own understanding of their identities. Here we adopt the identity / enactment approaches used by a number of scholars 
looking at the role of organizational identity in understanding stakeholder interactions

(Livesey, 2001; Cheney \& Christensen, 2000). Since identity is both socially bestowed and maintained through social interactions, we find it interesting to look at the impact of the emergence of the risk society and the breakdown of traditional institutions, or at least their authority, in relation to identity construction and its impact on stakeholder interactions.

\section{Late Modernity and Corporate Relations}

\subsection{Conditions of late modernity}

Global corporations face conditions of unprecedented risk associated with rapidly changing business conditions and expectations of their role in society. An interconnected set of risks, arguably a source of even more uncertainty, derive from the potential environmental impact and legacy issues of their activities. According to theorists of late modernity, organizations and individual citizens increasingly face these risks and uncertainties alone (Bauman, 2002; Beck, 2002; Giddens, 1991; Lash, 2002; Tsoukas, 1999). The 'disembedding' of traditional ways of life and the re-embedding of new ways (Giddens, 1990; Giddens, 1991) applies to the corporation as well as it does to the individual (Bauman, 2002; Beck and BeckGershein, 2002).

Tsoukas (1999: 511) draws from the work of Beck (1992), Giddens (1991), Lash and Urry (1994) and Thompson (1995) in order to summarize key features of the organizational setting of late modernity:

- action at a distance or distanciation; 
- detraditionalization or social reflexivity;

- an economy of risks based on a heightened perception of risk, and

- mediated communication.

For such theorists, these themes characterize an emergent and unplanned period of modernity: reflexive modernization. Society is confronted with the effects of risk that are beyond the management capability of the institutional system of industrial society which created them—as measured by the latter's institutionalized standards.

This self-confrontation is a form of reflexivity which goes beyond the cognitive realization of the processes by which knowledge is generated to include a critical self-awareness. The reflexivity is highly individualized, as the conditions of unprecedented uncertainty are associated with unavoidable processes of individualization, linked to global communication and transport services (Beck, 1992, Giddens, 1991, Lash, 2002). In this analysis, globalization and individualization are parallel processes (Lash, 2002).

\subsection{Stakeholder interaction}

Numerous writers, while not embracing reflexive modernization theory in its more comprehensive form, agree that one effect of the retreat of traditional systems of authority and their loss of legitimacy is increased internal and external stakeholder demand for more responsible corporate behaviour in terms of its relations with society and with the natural environment (Dunphy, Griffiths and Benn, 2003; Waddock, Bodwell, and Graves, 2002; Warhurst, 2001; Zadek, 2001). As a result a new period of stakeholder management and 
interaction has emerged. Other writers argue that because corporations now exercise social influence far beyond their economic function that they have an ethical responsibility to balance the requirements of multiple stakeholders, including the natural environment (Stanfield and Carroll, 2004). For corporations, the implications are new responsibilities such as voluntary codes of conduct, self-regulation, and the challenges of stakeholder participatory dialogue, often invoked through structures such as the community consultative committees which are the subject of this paper.

However, stakeholder interactions in the name of such ideals are faced with the problem of diffuse understandings of the key concepts of corporate social responsibility (CSR) and corporate sustainability (see Bergkamp, 2002). On the one hand, while the diffuse and open nature of the concepts enables the bringing together on common ground of previously antagonistic stakeholders, contestation concerning concept definition may preoccupy stakeholders and preclude collaborative outcomes. Organizational activities concerning CSR or corporate community relations thus may involve the formation of shifting, temporary ‘discourse coalitions’ (Beck, 1992; Hajer, 1997) or result in discursive struggles (Livesey, 2001) between corporations and other stakeholders. It would seem therefore, that the particular discourses characterizing these 'decentralized centres of sub-politics', comprising media publics, individual actors, community groups, government and corporate bodies, have the potential to further challenge the authority of traditional institutions of industrial society (Beck, 1995: 73).

\subsection{Identity and symbolic capital}


Reflexive modernization theory and its associated concepts of individualization and detraditionalization are persuasive when applied to identity construction. In post-industrial societies, identities are less likely to be inscribed by collectives such as the union, church or class. As a result of detraditionalization, people are freer to reflect, to self-examine and to redefine their identity (Bauman, 2002; Heelas, 1996). Organizations, too, operate in a less monolithic fashion, less according to rigid structural constraints and under self-regulatory regimes rather than the command and control regimes of the industrial era. Identitychallenging issues such as community relations and the impact of individuals on organizational identity are subjects of increasing interest in organization studies (eg Hatch and Schultz, 2004)

In late modernity, stores of symbolic capital or 'the accumulated prestige and recognition (legitimacy) that has been afforded to an actor' (Tsoukas, 1999: 506) are claimed as a major organizational resource. Credibility and reputation are intangible resources based in communication systems. In uncertain and turbulent business conditions, when decisions must be made between conflicting expert advice, the discursive struggles within these new arenas for decision-making are won on the grounds of reputation, trust and credibility (Livesey, 2001). The issue of identity is therefore crucial in these struggles between stakeholders in risk disputes.

However, identity stems from symbolic interaction in both internal and external relations of the organization. It follows that internal perceptions must align with 
external image if the organization is to build the cohesive identity necessary to build symbolic power. In other words, it is important for organizational insiders to buy in to the desired corporate identity and the espoused corporate values (Andriopoulos and Gosti, 2001; Meijs, 2002; Melwar and Jenkins, 2002; Scott and Lane, 2000). This raises the question of detraditionalization as it is debated by Heelas (1996). How can large corporations discard long-term traditions or systems of authority according to the demands of multiple internal and external stakeholders and still maintain a cohesive organizational identity?

The following analysis of the Orica study seeks to highlight these points, to investigate the extent to which identity and symbolic capital are pervasive in stakeholder dialogues and the extent to which they influence the outcomes of these dialogues.

\section{The study: Orica and the HCB waste}

\subsection{Methodology}

This paper uses the various "texts" of the dispute as its material (Fairclough, 1992). These texts are used as evidence of the various discursive repertoires (Wetherall \& Potter, 1992) that actors pull from in making arguments for their perspective on the issue. We use the word text in the communicative sense that it is seen as communicative acts be they in the form of spoken, written (physical or electronic) or visual communication These texts came from a variety of sources: Observation at stakeholder meetings, by examination of media reports, quoting or representing the views of the major stakeholder in the issue, and other texts, as well as by a number of interviews conducted with representatives of each of the 
major stakeholder groups involved in the decision-making concerning the waste (see Stakeholder Analysis below for a list of the major stakeholders). Each interviewee was questioned on their perceptions concerning the appropriate means for disposal, on barriers to reaching an understanding with other stakeholders and on the means by which the decision-making could be facilitated. All research material was read and manually coded for emergent themes by both researchers. These texts were used to uncover the discursive struggles between the actors in the study (see, Livesey, 2002), since they were seen to represent the institutionalised understandings of the issue in relation to the created identities of the various players in the struggle. We also draw on case material researched by other contributors to this volume and from other secondary documentation.

\subsection{Discourses of CPRC}

Our focus in this paper is on the discourses of the Community Participation and Review Committee (CPRC). The role of this Committee is stipulated to facilitate communications between the community, the NSW Environment Protection Agency (EPA) and Orica and to advise them on relevant proposals, including the monitoring and evaluation of the management plan for the destruction of the wastes. It includes representatives of local government, relevant independent experts, individual members of the community and representatives of local industry (such as Kelloggs, the cereal manufacturer), environmental and local community groups as well as Orica management (Lloyd-Smith, 2001). Other members of the community are welcome to attend the Committee as observers. The CPRC was mandatorily established in the 1990s in the wake of the publication of the National Waste Management Plan for HCB That it was mandatorily established rather than 
voluntary has undoubtedly lead to many of the conflicts that characterise this case.

However, the value, from an academic point of view, of studying this forum lies in the very fact that diverse discourse communities, who otherwise would not usually be in direct dialogue, have been forced together and forced t work towards a solution to the issue. The consequent clashes, misunderstandings, breakdown in trust and subsequent compromises have given unique insights into the processes of stakeholder dialogue.

\subsection{Stakeholder relations on the CPRC}

Initially government, radical environmentalists and industry specialists in Australia agreed on the unprecedented success of the scheduled waste management plans (Brown, 1999). However, the stakeholder relations of the CPRC as they have played out over the last nine years reflect growing lack of trust between corporate and local members of the CPRC.

Government agencies have been largely unwilling to intervene in support of more collaborative decision-making. In the stakeholder analysis that follows, we explore the reasons behind this shortfall in decision-making.

As other contributors have described, the key area of disputation in this decision-making episode has been whether the waste should be destroyed on site using Geomelt technology or transported elsewhere for disposal. Community representatives on the CPRC were concerned that changing economic conditions at Orica could mean a closing down of the chemicals section of the company and perhaps, that the company may use the name change from ICI Ltd to limit responsibility in the future (Lloyd-Smith, 2001). Their concerns became that the government was abrogating responsibility for the decision-making on the 
waste, and that it increasingly rested upon the CPRC itself to acquire the knowledge to assess the risks of waste destruction. They were suspicious that the Geomelt was chosen on a cost basis and were unsure of Orica's intention regarding insurance of the facility. They were not convinced by company assurances that the sale by the British parent was not an issue of liability for environmental legacy issues such as the toxic waste. Some CPRC members felt that Orica had always seen the CPRC as a source of legitimation and as a preemptive measure, forestalling a burst of public protest at the end (Brown, 1999), rather than a genuine tool for communication and consultation (Brown 1999).

\subsection{Communication issues}

Since its formation in 1996, the CPRC has met approximately three times per year and produces its own newsletter. Despite the controversy raging within the CPRC, the general level of local awareness and understanding of the issue has remained low, with only 38 per cent of a sample of local residents even being aware of the stockpile (Jensen-Lee, 2003). There has been little interest in the issue in the national media, most reports being in the local press, where the issue has overwhelmingly been portrayed as a local one (Jensen-Lee 2003). Other researchers report that local community representatives argue that a lack of resources made it difficult to raise public awareness of the hazards associated with the proposed destruction methodology (Jensen-Lee, 2003). The low level of interest by major media outlets also relates to the relatively minor role played by Greenpeace. In earlier confrontations, Greenpeace has had major media publicity for its revelations that ICI Ltd was involved in the dumping of toxic chemicals outside Sydney Heads. In this dispute, 
Greenpeace has been compromised by its stance against the transport of such toxic chemicals.

Orica's legal requirement to submit an Environmental Impact Statement (EIS) was also accompanied by considerable public consultation including nine public meetings and many thousands of letters being sent to local residents. The EIS was released in 2001. When it received more than 40 negative submissions, the Department of Planning referred the matter to a Commission of Inquiry. Submissions were received by the Commission from a wide range of stakeholders including local Councils, companies, peak environmental groups, resident action groups and local environment groups and the cereals manufacturer, Kelloggs. Kelloggs manufacturing plant is a long-term near neighbour of Orica and previously ICI and is very close to the proposed Geomelt facility site. The firms's friendly relationship with Orica was initially challenged by Orica's proposal to dispose on site. Government stakeholders, however, were largely supportive.

In July 2002 the Commissioner recommended to the Minister (for Planning) that the development should proceed on the grounds that the proposal presented no unacceptable risk to the community or the environment while recommending strict guidelines for its use. On Orica's count, about 20,000 newsletters were distributed to local residents describing the Commissioner's recommendations. This letter has been the subject of considerable dispute over issues such as 'who was to get the letter' and 'who saw the final draft' (Brown 2003). Orica and local environmental activists continued to 'beat a path to the Minister's 
door' (Brown 2003), while Kelloggs and Orica began to work together on a joint application to the Minister (Brown 2002).

The apparent stalemate and equivocation of the state government prompted the local Labour Party Member of Parliament to write to her fellow-Labour Party member, the Minister for Planning, requesting him to meet with the CPRC; her press release stated that 'local residents should have as much access as big corporations when Ministers make these decisions' (Keneally, 2003). In late 2003, the Minister convened an expert panel, comprising members approved of by community and Orica, to prepare a report. Community members then challenged the membership of this panel. As a result, one member, a leading Australian scientist, was replaced. In 2004, the Independent Expert Panel found against disposal on site and recommended 'the Geomelt destruction technology would adequately and safely destroy HCB waste under normal operating conditions but would be preferable to undertake the destruction process at an alternative, remote site'(DIPNR, 2004: 1).

Hence, more than two decades on from when its production was ceased, the final decision as to how and where to dispose of the waste is far from realisation. Despite, and indeed because of, its history of conflict and mistrust, the study provides insight into the types and causes of conflicts that pervade stakeholder interactions. The "involuntary" nature of this forum provides deep insights into the types of discursive struggles that have been described elsewhere (see, Livesey, 1999; Livesey, 2002) under conditions of voluntary interaction. It remains to be seen whether the CPRC can work together with other potential risk 
communities to reach an agreement on the method and site of disposal. For Orica, the exercise has been one of poor community relations, associated with considerable economic costs. The following analysis provides evidence to suggest why this may be the case and provides insights into how such an intractable situation can be ameliorated in the future.

\section{Stakeholder Analysis}

\subsection{Stakeholder discourse analysis}

In this section of the paper we identify salient stakeholders and attempt to understand the symbolic nature of the relationships between the actors and in relation to the issue of the disposal of the HCB wastes. An analysis is made of each stakeholder's symbolic investment in the issue, looking firstly at the types of discourses that each stakeholder employs and secondly at how these discourses shape their identity. The purpose is to suggest the sources of the conflict and mistrust associated with the CPRC. Because the focus of the paper is on the corporation we are particularly interested in how Orica and other corporate actors have contributed to this situation.

From the case history (see for instance, Brown this volume) we can identify the CPRC stakeholders around the HCB issue as Orica, other firms such as Kelloggs, national, state and local government, local community and environmental organizations with some overlap between local community and environmental organizations. 
We draw from case analysis of the HCB dispute (see Brown, this volume) to group stakeholders in quadrants according to their leading forms of discourse.

Figure 1 about here

We can define these discourses as follows. Scientific discourse is built upon the rational analysis of cause - effect relations between measurable variables. This discourse emphasises scientific facts, probabilities and risks. Both sides of the argument concerning disposal on-site have argued in scientific terms. According to the Chair of the CPRC, this body has come to exert 'strong moral and political suasion' through the way it has dealt with scientific knowledge' (Brown, 1999). In fact, the ICI and HCB information brochure set out by Orica in 1995 was based on questions posed by a community representative on the CPRC. Business discourse is built upon the application of models and concepts emerging through the quasi-scientific academic study of phenomenon limited to "the business world", drawn from many areas of the social sciences, and through practical experience. Bureaucratic discourse is concerned with the formation and application of procedures to deal with regularly occurring tasks in complex political systems. The emphasis is on reliability and consistency as well as transparency and political accountability. Environmental/ ethical discourse brings together a variety of claims concerning the natural environment (Hajer, 1997) built around key themes such as globality, crisis and the need for change (Irwin, 2001). Local discourses are built upon local knowledge and taken-forgranted understandings of relationships between the various stakeholders. Examples of each of these discourses are set out in Figure 1. 
From our research material we have identified the following initial key points concerning the stakeholder discourse analysis.

- The dominant discourse is the technoscientific discourse. This offers a "common language” across the stakeholder groups.

- Stakeholder groups such as international and national environmental groups have attempted to emphasise their scientific rationality by adhering to a strict scientific discourse. The result is a simplification of the issue which facilitates its politicisation and also separates this discourse from that of the local community.

- Stakeholder groups' identities are significantly influenced by their discourses.

\subsection{Stakeholder Identity Construction}

In this section of the paper, based upon an examination of the discourses of each of the leading stakeholders in the CPRC, we argue that the negotiations between the stakeholders reflected competing discourses in which actors prioritized the building and maintaining of identities rather than an active collaboration to solve the ongoing issue of the waste. We specifically focus on the way the corporate actors have constructed their identity in order to build symbolic capital. We see how, in the process, their relationships with other actors on the CPRC have been constrained, with major implications for the long-term costs to Orica, both in economic and reputational terms.

\subsubsection{The corporate actors}

Whilst different stakeholder groups may ostensibly pull from the same discourse, this approach does not explain apparent contradictions between certain stakeholders, e.g. 
Kelloggs and Orica. This situation occurs because each stakeholder does not solely rely on one discourse but draws from several as a result of its historical development and diversity within its membership. There are both dominant and secondary discourses.

Industry discourses are made up of several distinct discourses. For each company, identity is in part formed by the conscious or unconscious dominance of one of these discourses. In the below analysis we show that Orica's attempt to build symbolic capital through identity construction and hence influence the decision-making outcomes failed while Kelloggs succeeded in the same aim. We argue this outcome resulted from the dominance of a particular discourse and its effect on the symbolic capital of each firm. The dominant discourse influences the way the organization sees itself and the world around it in terms of issues, solutions, knowledge and communication.

Orica still maintains traditions and workplace culture inherited from its parent company. Originally most of the workforce was British and traditions, even symbolized in similar building design, remain with the firm today that originated with the British parent company. Its managers maintain their technoscientific identity through promoting the high levels of technical competence and high standards of technical safety inherited from ICI UK. According to the Custodian of the Waste, the Manager of the Botany site, and a longtime employee: 
Orica does have a recognizably high standard in safety - it is regarded as a benchmark organization.. We have ha d no staff affected by chemicals for yonks...We were always, there was always a solution around the corner... we were part of the ICI family, we thought the ICI scientists would find a solution to it (Benn, 2002).

The 'discursive struggle' between Orica and the local community was largely waged in terms of the uncertainty of the technology and unbounded nature of the risk. The community representatives on the CPRC constructed an understanding of the risk which implied that they could not be assured of protection from the destruction facility: ' It can't be fenced in - it goes all over us' (Community representative CPRC 2003).

In another instance, in a passage from the EIS statement prepared by local community members, they point out and critique Orica disclaimers which seek to waive company responsibility for the use of Geomelt, and to pass that responsibility to the designer and operator of the facility. The residents argue that in light of this, serious questions of accountability arise for the public, the development consent authority, the over- sighting agencies and the governments at both State \& Federal level. Orica attempted to counter these claims by building its legitimacy in terms of technical safety. The firm legitimates its proposal to dispose on site in terms of this expertise: 
The reasons we chose Botany were the materials are here, the people who know all about it are here so we've got medical staff, we've got occupational hygienists, we've got people who made the stuff...... and I think we've got the right culture for an operation like this here (Benn and Jones, 2002).

The selection of the title of 'Custodian of the Waste' for the site manager at Botany is a classic example of Orica's discourse constructing its identity as a responsible and worthy decision-maker for the waste’s disposal. To Orica's managers, the firm's willingness to participate in the CPRC discourse also reflects a new and more open culture: 'ICI Ltd worked in the inside world - all of a sudden we realised we had neighbours' (Benn, 2001).

In Orica's discourse, its recommendation for Geomelt was added further legitimacy by the opinion of the external technical expert. But the fact that this expert was paid for by Orica enabled the community members to construct the environmental consultants, expert advisors and Orica managers as members of the 'industrial science club' (Community representative CPRC, 2003).

Another issue that weakened Orica's symbolic representation was that Orica's discourse projected an evolving, even shifting identity that showed some disjunction between the past, present and likely future. On the one hand, as pointed out through the discourse of the Custodian of the Waste (longterm employee, chemical engineer and also manager of the 
Botany site), it strongly projected an image of its elite traditional technoscientific base. Yet on the other, the firm needed to reassure other stakeholders in the waste that a radically changed corporate culture from Orica's antecedent, ICI Australia:

ICI was arrogant - we're a big company. It did not want publicity - press releases were put out at $4.00 \mathrm{pm}$ (Benn, 2004b).

Orica's evolving identity is shown up in the following contradictory statements from Orica managers. While the Custodian of the Waste, a long-term onsite manager and chemical engineer, opined that 'remediation is a significant cost with no return' (Benn 2002), a more senior manager at the corporate level of the firm approaches the topic of remediation from the perspective of sustainable business.:

And that in general I think highlights the approach that we have to dealing with these legacy sites which is to say what is the new use of the site, what do we have to do to remediate it to that new usage and return it to new economic uses. ...the reality is you're far better to leave these sites in the condition to suit their future intended use ...... because coming back and having to sought these problems out later is far more expensive and far more damaging to the company's reputation in getting it sorted out (Benn, 2004b).

We also note from the study the importance of the communication systems to each of the CPRC actors. This also reflected their general awareness that legitimacy and 
credibility in disputes surrounded by such uncertainty rests upon more than scientific expertise. Orica’s long-term occupation of the Botany site did not help it win the discursive struggle - a number of safety breaches over the years were still resented by local community members. The struggle within the CPRC over the communication systems was really a struggle over Orica attempting to repair this image under the leadership of site managers from a previous era.

Kellogg's, in contrast to Orica, is a marketing company since its dominant discourse is focused on its corporate brand. This firm sees market and consumer issues, it seeks market knowledge and alignment and it communicates through marketing communication. It seeks to increase brand equity and building symbolic brand capital through developing a consumer orientation.

Kellogg's initially joined the opposition to destruction at Botany, stating that it had not been consulted during the initial environmental impact study. This statement from Kellogg’s showed their concern for the uncertainty of the technology:

The basis for our objection is that Orica is proposing to use unproven technology to dispose of this waste. Kellogg's Australia has stringent quality controls in place for all our breakfast cereals produced at the Botany plant and we pride ourselves on the quality of our foods (Davies, 2002: 5). 
The firm's discourse projected its identity as a manufacturer of 'wholesome' and 'safe' products. Kellogg's perceived the risks in terms of impact on their product quality and reputation, and were not convinced by Orica's risk assessment and management discourse which mainly focused on technical safety issues (Benn, 2004c).

Orica were always asking we're the professionals, we're the experts trust us and yet they were looking at it from an impact to health rather than.....and we're worried about product impact, product quality you know our concern was to children or to younger adults who maybe greater imposed upon by any byproducts or anything else that might have come through omissions. So we...our comfort level got probably less comfortable, our concerns probably stayed the same but we just got less comfortable with it and we tried to get more understanding (Benn, 2004c).

In Kellogg's discourse, the disposal facility was constructed as:

....a reputation liability... Kellogg's is a very....the brand name is very recognizable globally and within Australia and we're very conscious that, you know, it could be easily damaged....we have our own sort of little things that are around...... cornflake is a fragile thing so its reputation is a fragile thing (Benn, 2004c). 
As long-term neighbors, however, sharing a business discourse, the two corporations worked together to resolve these misunderstandings and relieve Kellogg's concerns about the technology. The following comments from a Kelloggs manager for instance, highlight how Orica recouped legitimacy in relation to its neighbour by promoting their specialist technoscientific expertise and hence status as a leading local business organization with a scientific capability:

I mean we sat down we went through (it) with Orica and it was good, I mean we worked together, there's no animosity but trying to understand better the technology...

how they verified they were complying was all based on the company and to an understanding that it's so specialized that probably the company was in a better position to say what is practical and what isn't (Benn, 2004c).

\subsubsection{Identity construction of other stakeholders}

The study shows Orica attempting to build its own symbolic capital through negative branding of other actors in the dispute. Figure 2 sets out examples illustrating Orica's discursive construction of stakeholder identity:

Figure 2 here

The Orica managers questioned the identity of the CPRC as representative of the community. 
Well I think certainly I learnt definitely during that stage that a community participation committee is not the community, they are representatives of the community but they're not actually the community, you're not getting to the man in the street (Benn, 2004a).

The minuses are how representative the CPRC is. Don't know what the answer is - we tried using the local press, we advertise and try to encourage people. The real challenge is to make sure these organizations have a broad representation. . There is the potential to become hijacked by people who are not members of the community (Benn, 2004b).

In the minds of these managers, it was not Orica's history or any breaches of trust with the community, but the firm's technical focus and lack of the political ability required to communicate scientific 'realities' to the community which let them down (Benn, 2004a).

Regulators figure in Orica's discourse as sharing a technoscientific culture and even personnel with Orica (Benn and Jones, 2002). But once again the discourse reveals a lack of a consistent theme, this time in its approach to government. Government is painted as an interventionist bureaucracy operating to impose certain management systems on the Botany site and its legacy issues. The government bureaucracy is also branded as ineffectual: 
one of the things that struck us early this year was the relationship between Orica and all levels of government in New South Wales was...it was neither good nor bad because it was virtually non existent (Benn, 2004b).

Orica managers construct local political interests as implacably opposed to industry in the Botany area, in association with Labor Party interests (Benn, 2004b).

International environmental groups have another perspective. Greenpeace’s opposition to transport of toxic waste has been used by Orica to justify the case against transport of the waste. The 'biggest' issue was described as:

... transporting the material from wherever, all around Australia, to that site. It was a very significant issue. All the national groups, the green groups like Greenpeace and all those have openly said that that they don't think there is a chance of doing it at an offsite location (Benn, 2001).

Greenpeace was limited in its capability to influence the decision-making because its international identity was tied to both anti-incineration and transport of toxic waste, a factor which Orica was able to exploit in its arguments in support of the Geomelt technology. 
Now at the day I announced it Greenpeace were at the meeting of the CPRC were quite willing to accept the technology but two days later I got an email from Greenpeace International saying that they were greatly opposed. ${ }^{\mathrm{C}}$

(Alternative technologies to Geomelt) were politically appealing to NGO’s because they were not incineration. ... In some recent arguments there has not been an understanding of technology's advancement in recent years such as Geomelt (Benn, 2004b).

\subsection{Discussion}

\subsection{The challenge of individualization}

Despite the initial success in the development of a collaborative forum such as the CPRC, key challenges have emerged for Orica, for the community in the Botany area and for government in dealing with this dispute, challenges which are strongly influenced by conditions of individualization. An early and crucial decision, upon which all subsequent events have turned, reflects the conditions of the individualized society. This was the decision not to have a centralised high temperature incinerator, but to have 'local, decentralised solutions' to the disposal of the waste. In other words, Orica must manage its own waste, or rather the inherited waste from ICI Ltd. Aside from the initial construction of the waste management plans, government stakeholders were little in evidence. The emergence of a more individualized and reflexive local community proved a key challenge for the corporate actors. The CPRC included representatives of the local community who were determined for some control over their own exposure to the risks from disposal of the

\footnotetext{
${ }^{\mathrm{c}}$ Interview with Bruce Gotting, 30 July 2004 Botany.
} 
waste and who were not prepared to leave the decision-making to experts. With so few of the local community even aware of the waste, the community can hardly be described as highly reflexive. We must therefore be circumspect in arguing that the study reflects the processes of individualization and high levels of reflexivity as characterised by theorists of late modernity.

In view of this lack of more generalised reflexivity, the study highlights the challenges for community stakeholders in such risk communities as that at Botany. The identity of the community representatives on the CPRC is very much bound to the credibility and informal scientific expertise of the leading activists - who have developed a store of considerable knowledge about the disposal of toxic waste (Brown, 1999). It is thus highly personal, noninstitutionalized and less secure for the long-term as a community resource.

\subsection{Identity and symbolic capital}

It is clear from the study and the accompanying discourse analysis that Orica are tied by their own identity as a chemical engineering company and their belief in their own professionalism and expertise regarding the disposal of toxic waste. Orica's identity is formed on the basis of its understanding of itself as a technoscientific chemical engineering company first and foremost. Orica sees technological issues and solutions, they seek scientific and technical knowledge and they communicate in this language. Whilst the firm does communicate through other discourses they remain subservient. 
It is also clear why Orica have not been effective in communicating their legitimacy as managers of the waste disposal to the CPRC stakeholders. On the firm's own admittance, it previously paid little attention to stakeholders such as the local community. When they did begin engaging their stakeholders in dialogue they tended to focus on these were they could 'speak the same language'; that is, where there was a discursive overlap. Their attempt to construct the discourse of the local community members of the CPRC as NIMBY in the end failed to convince the government agencies whose decision it finally was as to how and where to destroy the waste. Lending support to the theory of late modernity as set out previously, the local community at Botany demonstrated an individualized reflexivity that enabled them to counter Orica’s credibility in the technoscientific arena. Embracing scientific discourse enabled the local opposition to abstract their cause away from the NIMBY syndrome. Given the responsibility of looking after their own destiny, as this theory predicts, the local representatives on the CPRC did just that. The community had to develop their own store of technical knowledge, as they did not trust the expert paid for by Orica. Government would not fund an independent expert. In this way, the local community developed their discursive advantage: local knowledge integrated into a new capacity for technoscientific communication which lent considerable legitimacy to their case against disposal on site.

Orica's further problem was that its internally held identity, still strongly influenced by its parent company and maintained in the attitudes of longtime employees at the Botany plant, 
was not in alignment with the new rhetoric of community relations espoused at the corporate level by more senior managers. As Tsoukas (1999) has pointed out in his study of the Brent Spar case, scientific rationality does not always win out in the symbolic realm. Orica was caught in the negotiations over disposal of the waste between its dependence on its technoscientific capability as a source of symbolic capital and its need to break down its image as an 'arrogant' organization (Benn 2004b).

\subsection{Symbolic capital and uncertainty}

Similarities and differences between the discourses of Kellogg's and Orica highlight the challenges confronting corporations in their risk management strategies in an era of individualization and social reflexivity. For a number of reasons, Kellogg's negotiated a dialogue with Orica based on discursive overlap and a shared corporate understanding that little government support and involvement was to be forthcoming. Each corporation appeared aware of the contingent nature of the corporate 'licence to operate' (Elkington, 1998) in the face of low levels of government involvement and a strengthening civil society (Zadek, 2001). But as a consumer-based organization, Kellogg's showed itself to be much more protective of its reputational or symbolic capital in the global market. Kellogg's discourse showed a high understanding of the relationship between symbolic capital and uncertainty, demonstrating an awareness that global consumers would rapidly flee the brand if uncertainties surrounding the technology damaged its image as a manufacturer of healthy food, particularly for the consumption of young people. 
In contrast, Orica confronted an emergent public at the local level. Orica’s legitimacy as a technoscientific organization rested on scientific expertise and reputation for health and safety. But to members of the local risk community, although not to consumers or shareholders, Orica’s legitimacy had long been undermined by industrial accidents on site. Now with the CPRC in place, this public had some teeth. It is testimony to the barriers that some corporations establish between themselves and the outside world that the well-documented shift to the more open internal organizational culture at Orica (Mealor, 1999; Stace and Dunphy, 2001) had not translated into more transparent relationship with these external stakeholders from the local community.

\subsection{Tradition-maintenance or detraditionalization?}

Orica's heritage of an elite technoscientific organization did not allow the firm to empathise with other organizations, even those with such a long and neighbourly relationship as Kellogg's. It carried a double burden from the past: a heritage of closed, self-referential culture and a stockpile of toxic waste. In that sense, the study does not support the radical aspect of detraditionalization theory of late modernity. Indeed, none of the key stakeholders showed themselves as able to escape their own set of traditions and redefine their identity in order to collaborate actively on the CPRC. For Orica and the local Botany community representatives on the CPRC, perceptions and expectations of each other derived from an industrial past. 
Greenpeace found it very difficult to redefine itself away from the anti-incineration, transport of toxic waste profile, which Orica readily exploited to support its argument on site. It cannot defend the community in the national media, as their reputation, crucial to winning their campaigns and membership numbers, is dependent on their defence of the global environment. On the global stage, Greenpeace has made itself known as opposed to the transfer of toxic waste - so cannot here defend the local community against disposal on site. The solution reached by many other countries to the problem of toxic waste is high temperature incineration. But Greenpeace’s reputation is also tied to anti-incineration.

This study as an example of co-existence of detraditionalization and tradition-conformance or maintenance, adds weight to Heelas' (1996) concept that traditions may come in many forms aside from the authority of a collective, such as is still espoused by the community members of the CPRC. They may be routines, or entrenched cultures in a corporation, such as with Orica, or strongly communicated public images of an organization, such as with Greenpeace. As Heelas ( 1996: 11) points out, these ‘quasi-traditions’ still ‘serve to provide sustained voices of established authority’.

Finally, each of the stakeholders figuring largely in this study has commented on lack of government involvement and direction. We cannot analyse this finding further as we have not been able to obtain access to government agency representatives due to the decisionmaking that has been in progress since 2002 by either the Commission of Inquiry or the Independent Expert Panel. Now those recommendations have been made it is hoped that further research will examine the role played by government stakeholders in relation to the 
community/ corporate relations and the individualization and detraditionalization thesis of late modernity.

Further research could also probe the discursive history of the CPRC in light of Hardy et al (2006) recent review of productive collaboration. This work indicates that a combination of 'assertive' talk (where the stakeholders maintain strong identification with their own organization ) and ‘cooperative’ talk (where the stakeholders identify with shared interests of the collaborators) produces effective collaboration.

\subsection{Conclusion}

The issue of improving community/ public/ private sector relationships underpins this study. The discourse analysis of its stakeholders reveal the challenges faced by contemporary corporations as they must develop a strong internal identity to address conditions of mounting uncertainty, yet evolve so as to deliver on community relations requirements of flexibility, transparency and openness. We have noted that the stakeholder interaction in this study reflects competing discourses in which corporate actors prioritize the building and maintaining of identity and symbolic capital rather than an active collaboration to solve the ongoing issue of the waste. As well, issues of access to expert knowledge have highlighted the relationship between conditions of uncertainty, technoscientific expertise and identity. We have noted changes in the discourse of the chemicals company we have studied as it has faced some of these challenges of decision-making. We are concerned, however, that this may not necessarily mean an improvement in corporate/ community relations. For 
risk communities such as Botany, the issue will be how to deal not with an Orica shut off behind its self-perception of technoscientific credibility, but an Orica newly versed in the language of public relations. Given our observations as to the strength of the quasi-traditions in such organizations as Orica, we argue that the issue will then be to distinguish rhetoric from reality and the stakeholder forums that could assist in this task.

Our analysis lent some support to the general predictions of late modernity theory concerning the increasing trend towards detraditionalization and individualization. Individual members of the local community were shown to be redefining their identity and rewriting the conditions for their own survival through their participation in the CPRC. The paper also raises the possibility that such theory can also be applied at the organizational level, with organizational representatives, such as from Greenpeace, also involved in rewriting their identity. Yet each stakeholder remained constrained under some traditional authority. The question of whether organizational identity can in fact be separated from identity of prominent individuals within organizations and the interplay between these forms of identity is a question that could be addressed through further analysis of this study. We conclude that the study demonstrates the co-existence of social processes of individualization and detraditionalization with quasi-traditions which maintain authority, thus challenging the radical distinctions made in the literature between modernity and late or reflexive modernity. The co-existence of these processes and traditions raises questions concerning the forums necessary to encourage stakeholder reflexivity. 


\section{References}

Australian Broadcasting Corporation (ABC), 2005. Botany Bay left with chemical legacy.

The 7.30 Report, Reporter J. Harley, TV program transcript, Broadcast: 08/02/2005.

Online. Available at: http://www.abc.net.au/7.30/content/2005/s1298618.htm (accessed 14

July 2006.)

Andriopoulos, C. and Gosti, M., 2001. Living the Corporate Identity: Case Studies from the

Creative Industry. Corporate Reputation Review. 4( 2), 144-154.

Bauman, Z., 2002. Preface in: U. Beck and E. Beck-Germstein, Individualization, London, Sage Publications.

Beck, U. (trans. Mark Ritter).,1992. The Risk Society, London, Sage..

Beck, U., 1995. Ecological Politics in the Age of Risk, Cambridge, Polity Press.

Beck, U., 1999. World Risk Society, Cambridge, Polity Press.

Beck, U. and Beck-Gershein, E., 2002. Individualization. London, Sage Publications.

Beder, S., 1991. 'Hazardous Waste: An Intractable Problem’, The Bulletin, 30 July 1991, pp92-96

Beetham, D., 1993. Liberal democracy and the limits of $\sqsubset$ emocratization. In: D. Held (ed), Prospects for Democracy, Cambridge, Polity Press, pp. 55-73. 
Bellamy, R., 1999, Liberalism. In: R. Eatwell and A. Wright (eds), Contemporary Political Ideologies, Pinter, London, pp. 23-50.

Benn, S. 2001. Interview with Site Manager, Botany Industrial Park (comprising the organizations Orica, Quenos and Hunstman). 20 July.

Benn, S. 2002. Interview with Site Manager, Botany Industrial Park (comprising the organizations Orica, Quenos and Hunstman). 30 November.

Benn, S. 2004a. Interview with Site Manager, Botany Industrial Park (comprising the organizations Orica, Quenos and Hunstman). 30 July

Benn, S. 2004b. Interview with Orica General Manager, Technology and Environment. 20 October.

Benn, S. 2004c Interview with. Kellogg’s Quality Asia Pacific Director. 3 September 2004. Benn, S. and Jones, R. 2002. Interview with Site Manager, Botany Industrial Park (comprising the organizations Orica, Quenos and Hunstman). 2 July.

Berger, P.L. \& Luckmann, T., 1991. The Social Construction of Reality: A Treatise in the Sociology of Knowledge, London, Penguin.

Bergkamp, L., 2002. Corporate governance and social responsibility: A new sustainability paradigm. European Environmental Law Review, May, 136-152.

Blumer, H., 1969. Symbolic Interactionism: Perspective and Method. Berkeley, CA., University of California Press.

Cheney, G, \& Christensen, L.T., 2000. Organizational Identity: Linkages between Internal and External Communication. In: F. M. Jablin \& L. L. Putnam (Eds.), New Handbook of 
Organizational Communication - Advances in Theory, Research and Methods, Thousand Oaks, CA., Sage, pp. 231-269.

Brown, P., 1999. Our Affair with Hexachlorbenzene: a case study in Australian chemicals management. The Environment: Risks and Opportunities. Third Annual International Public Policy and Social Science Conference, Oxford.

Brown, P., Chair CPRC, Personal communication to S. Benn. Sydney, 12 December 2002

Brown, P., Chair CPRC, Personal communication to S. Benn. Sydney, 15 October 2003

Community representative, CPRC. 2003. Interview with S. Benn., Sydney, 20 June 2003.

Davies, A., 2002. Kellogg’s joins residents to fight toxic plant. Sydney Morning Herald, 5. 21 May 2002.

Dean, M., 1992. A genealogy of the government of poverty. Economy and Society, 21, 215-251.

Department of Infrastructure, Planning and Natural Resources (DIPNR), 'What's new', at http:www.dipnr.nsw.gov.au accessed 18 October, 2004.

Dunphy, D., Griffiths, A and Benn, S., 2003. Organizational Change for Corporate Sustainability. Routledge, London.

Elkington, J., 1998. Cannibals with Forks, London, Capstone.

Fairclough, N., 1992. Discourse and Social Change, Cambridge, Polity Press 
Gergen, K.G., 1982. Towards Transformation in Social Knowledge, New York, SpringerVerlag.

Giddens, A., 1990. The Consequences of Modernity, Cambridge, Polity Press.

Giddens, A., 1991. Modernity and Self-Identity: Self and Society in the Late Modern Age, Cambridge, Polity Press.

Grant, D., Michelson, G., Oswick, C., Wailes, N. 2005, Guest editorial: discourse and organizational change. Journal of Organizational Change Management, 18, 6-15

Greenpeace, Briefing, 'Toxic Incineration Threat to Botany'. Available at:

http://www.greenpeace.org.au/toxics/pdfs/orica.pdf (accessed 14 July 2006.)

Hajer, M., 1997. The Politics of Environmental Discourse. Oxford, Oxford University Press.

HCB Community Information Session, Community Participation and Review Committee (CP\&RC) submission by the Community members. Environmental Impact Statement The Construction and Operation of a Proposed Hexachlorobenzene (HCB) Waste Destruction Facility At The Orica Site in Botany. Prepared on behalf of the community representatives on CP\&RC by Mrs. Nancy Hillier Mr. Richard Smolenski 3rd October 2001. Online. Available at: http://www.oztoxics.org/research/3000_hcbweb/library/eis/eis_0005.html (accessed 16 July 2006.)

Hardy, C, Lawrence, T. and Grant, D., 2005. 'Discourse and Collaboration: The Role of Conversations and Collective Identity', Academy of Management Review, 60, 58-77.

Hatch, M.J., Schultz, M. 2004. Organizational Identity: A Reader. Oxford University Press, Oxford. 
Heelas, P., 1996. Introduction: Detraditionalization and its Rivals. In: P. Heelas, S. Lash and P. Morris (1996), Detraditionalisation, Oxford, Blackwell, pp. 1-20.

M. Hyman, quoted at Stockholm Convention of Persistent Organic Pollutants, National Implementation Plan Seminar, Canberra, 1 December 2004, at http://72.14.203.104/search?q=cache:4QrxokX4-oJ:www.biodiversity.ea.gov.au/settlements/chemicals/international/pubs/seminar1.pdf + waste + management + plans + government $+\mathrm{HCB}+$ Orica\&hl=en \&gl=au\&ct=clnk\&cd=1 $\underline{0}$ accessed 17 July 2006.

Irwin, A., 2001. Sociology and the Environment, Cambridge, Polity Press.

Jensen-Lee, C., 2003. Orica, HCB and Geomelt: The Commission of Inquiry for Environment and Planning into Orica's Proposal to Build a HCB Waste Destruction Facility at Botany Using Geomelt Technology, Working Paper, School of Social Science and Policy, UNSW, Sydney.

Keneally K., 2003. Planning Minister should listen to local residents on HCB waste. Media Release from Member for Heffron, NSW House of Representatives, Sydney. 22 June 2003.

Kenneally, K. 2004. Member NSW House of Representatives. Interview with S. Benn.

Pagewood, 2 November 2004.

Lash , S. and Urry, J., 1994. Economies of Signs and Space, London, Thousand Oaks.

Lash, S. 2002., Preface. In: Beck, U. and Beck-Gershein, E. 2002. Individualization.

London, Sage Publications.

Livesey, S., 2001. Eco-Identity as Discursive Struggle: Royal Dutch/ Shell, Brent spar and Nigeria. The Journal of Business Communication. 38, (1), 58-89. 
Livesey, S., (2002). Global Warming Wars: Rhetorical and Discourse Analytic Approaches to Exxon Mobil's Corporate Public Discourse, Journal of Business Communication, 39(1), $117-148$.

Lloyd-Smith, M., 2001. HCB Community Information System. Online. Available at: http://www.oztoxics.org/. (accessed 15 July 2001)

Matten, D. and Crane, A., 2005. Corporate citizenship: toward an extended theoretical conceptualization. Academy of Management Review, 30(1), 166-180.

McDonell, G., 1997. Scientific and Everyday Knowledge: Trust and the Politics of Everyday Initiatives, Social Studies of Science, 27, 819-863.

Mealor, T. 1999. Catalysts, Continuity and Change: Workplace Restructuring in the Chemical Industry, unpublished PhD thesis, Australian Graduate School of Management, University of New South Wales.

Meijs, M., 2002. The Myth of Manageability of Corporate Identity. Corporate Reputation Review, 5 (1),20-34.

Melawar, T. and Jenkins, E. 2002. Defining the Organising Identity Construct.Corporation Reputation Review, 5, 76-90.

NAB and Scheduled Wastes Management Group 2000. Solutions, Canberra, Environment Australia.

Nahapiet, J. \& Ghoshal, S., 1998. Social Capital, Intellectual Capital and the Organizational Advantage, Academy of Management Review, 23, 242-266. 
Petrick, J., Scherer, R., Brodzinski, J., Quinnn, J. and Fall Ainina, M., 1999. ‘Global leadership skills and reputational capital: Intangible resources for sustainable competitive advantage', Academy of Management Executive, 13 (1), 58-69.

Rorty, R., 1979. Philosophy and the Mirror of Nature|, Princeton, NJ., Princeton University Press.

Scott, S. G. and Lane, V.R., 2000. A Stakeholder Approach to Organizational Identity. Academy of Management Review, 25, 43-62.

Simmel, G. (1964)., The Sociology of Georg Simmel, London, The Free Press.

Stace, D. and Dunphy, D., 2001. Beyond the Boundaries: Leading and Re-creating the Successful Enterprise, Sydney, McGraw Hill

Stanfield, J. and Carroll, M. 2004., Governance and the Legitimacy of Corporate Power: A Path for Convergence of Heterodox Economics?. Journal of Economic Issues 38 (2), 363371.

Thompson, J., 1995. The Media of Modernity. Cambridge, Polity Press.

Tsoukas, H., 1999. David and Goliath in the Risk Society’ Organization, 6(3), 499-526.

Waddock, S., Bodwell, C. and Graves, S.,, 2002. Academy of Management Executive, 16(2), 132-149.

Warhurst, A., 2001. Corporate citizenship as corporate social investment. Journal of Corporate Citizenship, 1, 57-73.

Weatherall, M. \& Potter, J., 1992. Mapping the Language of Racism: Discourse and the legitimation of exploitation. New York, Columbia University Press. 
Weick, K., 1979. The Social Psychology of Organising, London, McGraw-Hill.

Zadek, S., 2001. The Civil Corporation, London, Earthscan Publications. 
Figure 1: CPRC stakeholder discourses

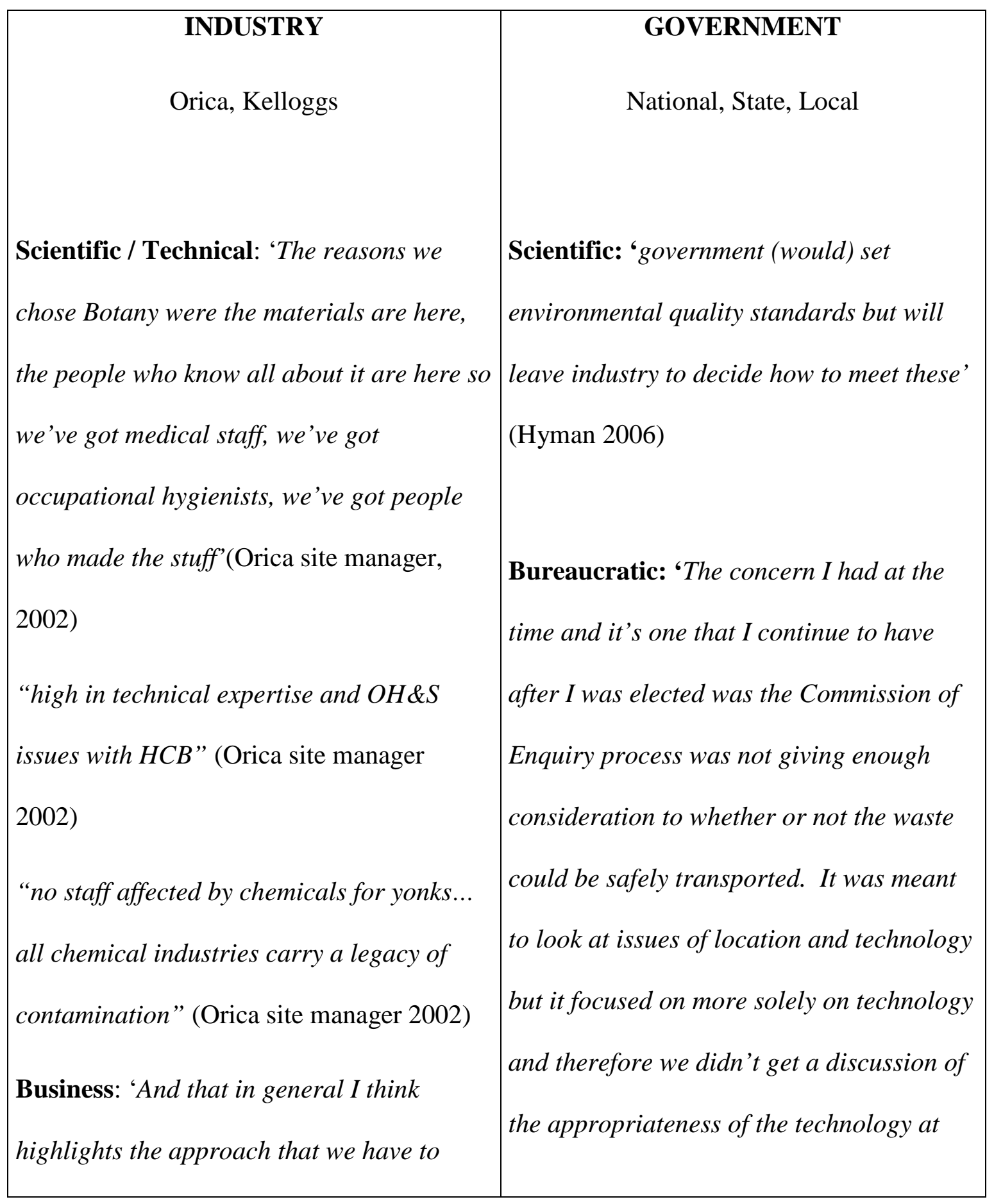




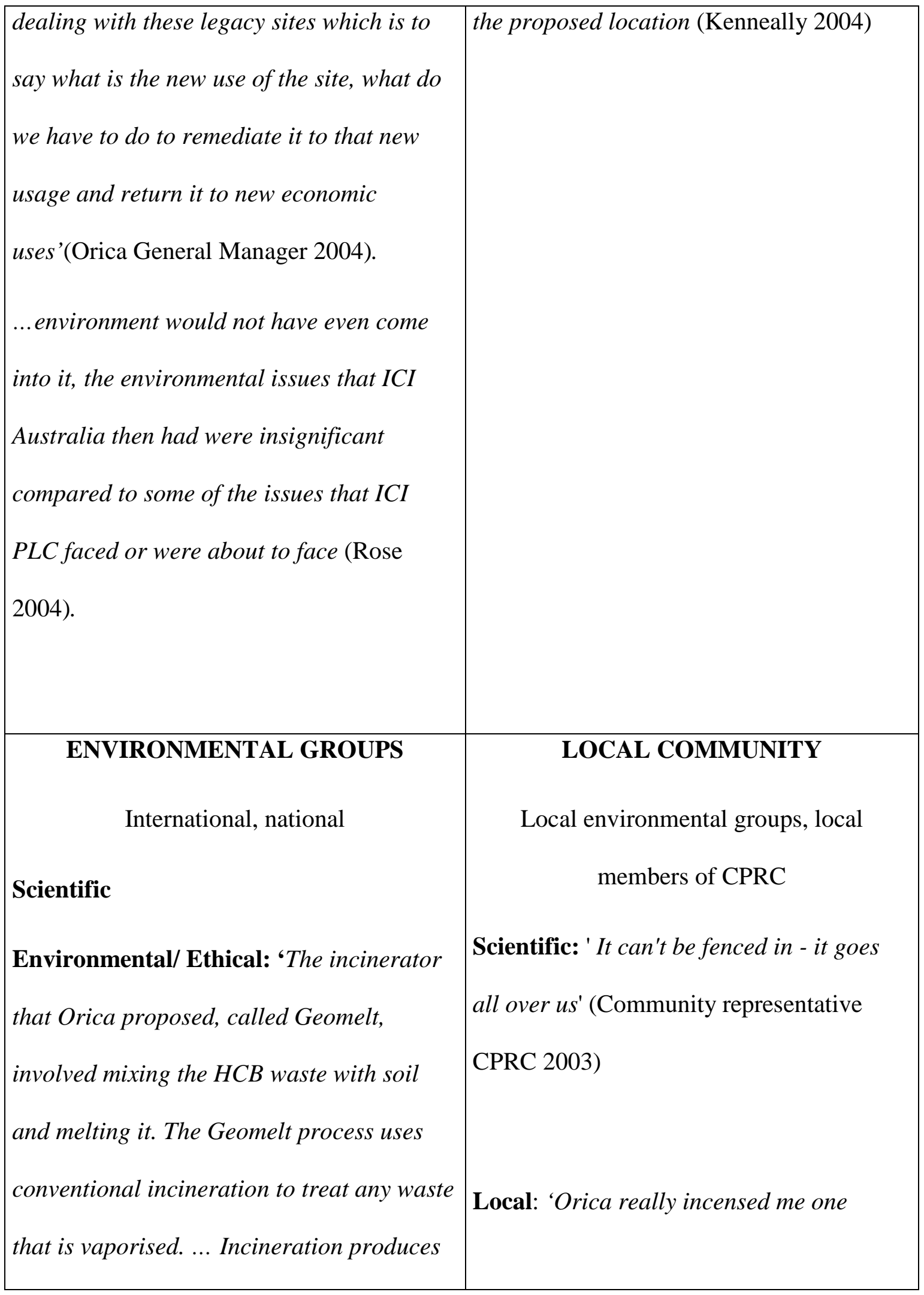




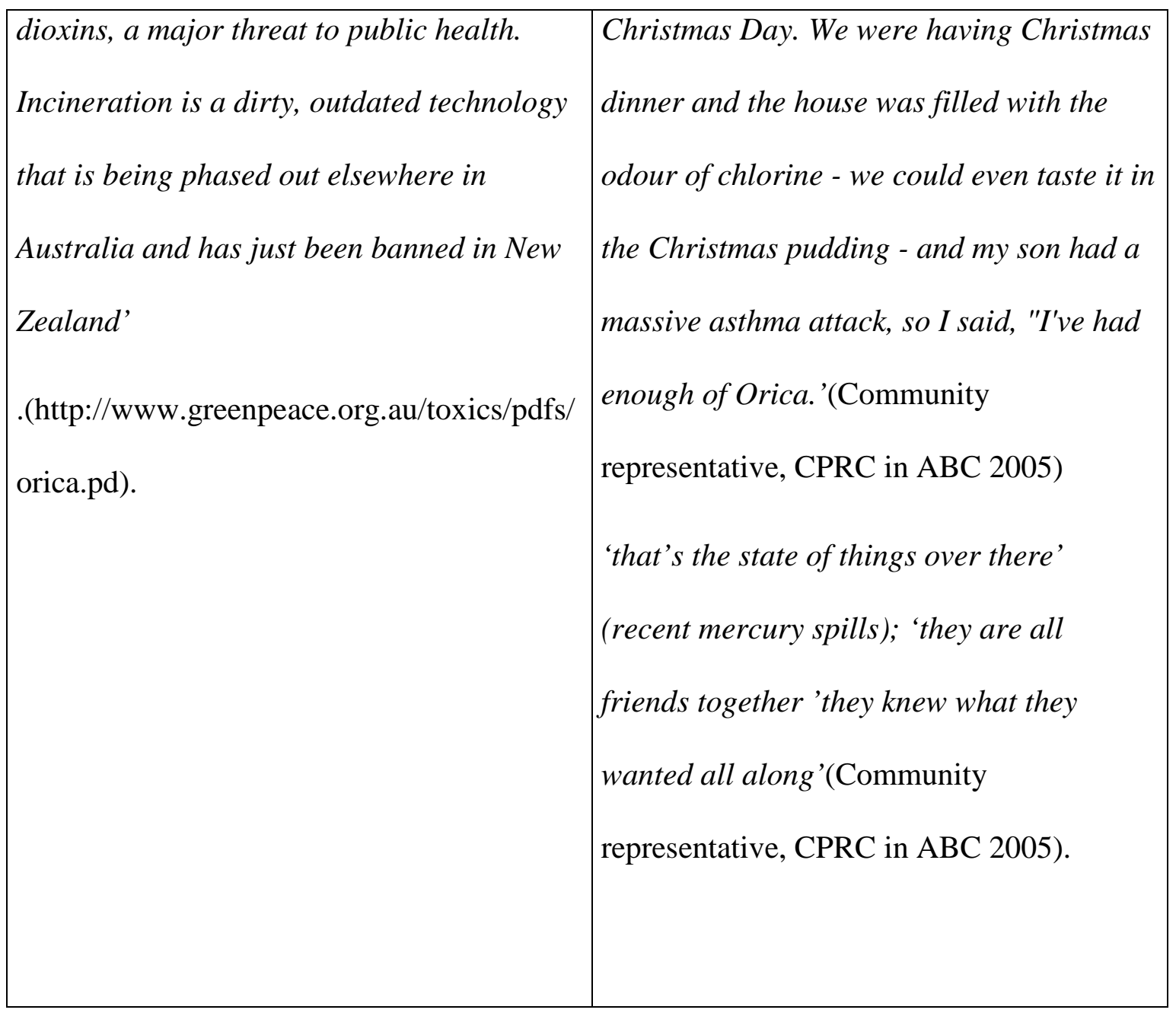


Figure 2: Examples of Orica's construction of stakeholder identity

\begin{tabular}{|c|c|c|}
\hline Stakeholder & Discourse & Identity \\
\hline $\begin{array}{l}\text { Local community } \\
\text { members of CPRC }\end{array}$ & $\begin{array}{l}\text { : a result of perception rather than } \\
\text { reality. Emissions were to be well } \\
\text { within international emissions limit. } \\
\text { 'it all goes back to the fact that it's } \\
\text { local - noise is also an issue' } \\
\text { ' (local community member) is very } \\
\text { close to the Labour Party' (Rose 2004) }\end{array}$ & $\begin{array}{l}\text { - As NIMBY } \\
\text { - As politically and } \\
\text { industrially opponents } \\
\text { biased against Orica }\end{array}$ \\
\hline Government & $\begin{array}{l}\text {..one of the things that struck us early } \\
\text { this year was the relationship between } \\
\text { Orica and all levels of government in } \\
\text { New South Wales was...it was neither } \\
\text { good nor bad because it was virtually } \\
\text { non existent. (Rose 2004) }\end{array}$ & $\begin{array}{l}\text { As ineffectual } \\
\text { bureaucracies }\end{array}$ \\
\hline Orica & $\begin{array}{l}\text { We were always, there was always a } \\
\text { solution around the corner... we were } \\
\text { part of the ICI family, we thought the } \\
\text { ICI scientists would find a solution to it. }\end{array}$ & $\begin{array}{l}\text { As a centre of expertise } \\
\text { in chemicals } \\
\text { management }\end{array}$ \\
\hline
\end{tabular}




\begin{tabular}{|c|c|c|}
\hline & (Gotting 2002) & \\
\hline Greenpeace & $\begin{array}{l}\text {... transporting the material from } \\
\text { wherever, all around Australia, to that } \\
\text { site. It was a very significant issue. All } \\
\text { the national groups, the green groups } \\
\text { like Greenpeace and all those have } \\
\text { openly said that that they don't think } \\
\text { there is a chance of doing it at an } \\
\text { offsite location. (Gotting 2001) }\end{array}$ & $\begin{array}{l}\text { As international } \\
\text { activists against } \\
\text { incineration and the } \\
\text { transport of toxic waste }\end{array}$ \\
\hline
\end{tabular}


